\title{
Response to letter to the editor regarding "Utility of patient decision aids (PDA) in stress urinary incontinence surgery"
}

\section{Swati Jha ${ }^{1}$ (D) Jonathan Duckett ${ }^{2}$}

Received: 15 September 2019 / Accepted: 3 October 2019 / Published online: 2 December 2019

(C) The International Urogynecological Association 2019

\section{Dear Editor,}

We thank Ong et al. for their interest in our article "Utility of patient decision aids (PDA) in stress urinary incontinence surgery" [1]. Regarding the PDA that was used, we have declared in the methodology that neither the development nor the content was the subject of this paper. This PDA has since been amalgamated with the NICE PDA, which replaces it, and there is no further ongoing work or validation intended for the PDA used in this survey. We will be undertaking validation of the NICE PDA going forwards.

It was not intended as part of the survey to assess the impact on patient choice of the pause on the use of vaginal mesh for incontinence in the UK, and we have made it clear in the discussion that the pause has limited the interpretation of the results.
We would also accept that there is no precedence for the functionality of the PDA and again this has been made clear in the discussion. We have mentioned that there was no comparator either before the introduction of the PDA or from analysis of women who did not receive the PDA.

\section{References}

1. Jha S, Duckett J. Utility of patient decision aids (PDA) in stress urinary incontinence surgery. Int Urogynecol J. 2019;30(9):1483-6.

Publisher's note Springer Nature remains neutral with regard to jurisdictional claims in published maps and institutional affiliations.

This response refers to the letter available at https://doi.org/10.1007/ s00192-019-04118-1

Swati Jha

Swati.Jha1@nhs.net

1 Department of Urogynaecology, Sheffield Teaching Hospitals NHS Foundation Trust, Jessop Wing, Tree Root Walk, Sheffield S10 2SF, UK

2 Department of Obstetrics and Gynaecology, Medway Hospital, Windmill Road, Gillingham, Kent ME7 5NY, UK 